\title{
LIFE HISTORY OF ABEDUS HERBERTI IN CENTRAL ARIZONA (HEMIPTERA: BELOSTOMATIDAE)*
}

\author{
By Robert L. Smith \\ Department of Zoology \\ Arizona State University \\ Tempe, Arizona 8528I
}

\section{INTRODUCTION}

Torre Bueno in 1906 noted the meagerness of information on the biology and immature stages of aquatic Hemiptera. Although this condition has changed somewhat in the more than 60 subsequent years, complete life histories for representatives of only two of the five genera belonging to the subfamily Belostomatinae (Lauck and Menke 196I) are available. Belostoma is represented by $B$. $A$ fumineum Say (Torre Bueno 1906), B. oxyurum (Dufour), B. bifoveolatum Spinola (Schnack I97I), and B. malkini Lauck (Cullen 1969). The Old World genus Limnogeton is represented by $L$. fieberi Mayr (Voelker 1968). Menke (1960) was successful in bringing a single individual Abedus dilatatus (Say) to its fifth instar, at which time it died. Life histories for representatives of the genus Lethocerus include: L. americanus (Leidy) (Rankin 1935), L. cordofanus Mayr (nec. L. niloticus Stål) (Tawfik 1969), L. mazzai De Carlo (De Carlo 1962), and L. maximus De Carlo (Cullen 1969). Nothing is known of the immature stages of Horvathinia (subfamily Horvathiniinae, Lauck and Menke 1961). The taxonomy and distribution of Abedus herberti, as well as a behavioral and ecological sketch of the genus, is provided by Menke (1960).

\section{Methods and Materials}

I collected adult bugs, including males encumbered with eggs, with the aid of a gasoline lantern at night from the following central Arizona localities: Sycamore Creek, Maricopa County, near Sunflower; Camp Creek, Maricopa County, near Carefree; and Tule Creek, Yavapai County, in the Bradshaw Mountains. ${ }^{1}$ Plastic bags containing stream water isolated individuals for transport to the

\footnotetext{
${ }^{1}$ Menke's 1960 revision recognizes polytypy in $A$. herberti. The central Arizona specimens studied in this paper belong to "subspecies herberti" in contradistinction to "subspecies utahensis."

*Manuscript received by the editor July 1, 1974.
} 
laboratory. Plastic washbasins ( 5 by 26 by $30 \mathrm{~cm}$ ) containing clean gravel and deionized water housed bugs in the laboratory. Finger bowls ( 10.5 by $4.5 \mathrm{~cm}$ ), provided with aquarium gravel and deionized water to a depth of about $4 \mathrm{~cm}$, received hatchlings obtained from eggs of field-captured encumbered males. Gravid females, paired with unencumbered males, produced fresh eggs for incubation studies. First and second instar nymphs were fed on cultured vestigial winged Drosophila which were floated on the water's surface. Third and fourth instars received legless crickets (Acheta domestica), and fifth instars ate intact crickets. I renewed food and water every other day, and recorded molts which had occurred each day. Cast skins were preserved in seventy percent alcohol, one percent glycerin for study and measurement. Open water temperature in the laboratory was a reasonably constant $\mathrm{I} 8 \mathrm{C}( \pm 0.5 \mathrm{C})$.

I observed hatching and used still and motion picture photography to record this event for analysis. I measured eggs, first, second, and third instar nymphs and the legs of fourth and fifth instars using a stereoscope ocular micrometer, and the bodies of fourth and fifth instars with a dial caliper.

\section{Eggs, Incubation, and Hatching}

EGGS

The eggs of Abedus are always laid on the back of the male (Fig. IA). Oviposition, which continues for 12-48 hours in the laboratory, alternates with copulation. Encumbered males are found throughout the year in Arizona. A detailed study of courtship and male brooding behavior in $A$. herberti will be presented elsewhere (Smith, in prep.).

A mucinous glue is secreted by the female prior to the deposition of each egg starting at the apex of the male's hemelytra and proceeding forward, uniformly covering the male's back up to and sometimes including the pronotum. It is usually the case that males carry the eggs of only one female, but polygynous matings apparently do occur (Menke 1960). I inferred from data on hatching, that of seven encumbered field captured males, only one individual had consorted with two females to acquire his load of eggs. In this instance, 72 eggs hatched over a five day period, this followed by three days during which no eggs hatched. The remaining is eggs hatched over a 24 hour period. In all other cases, hatching occurred more or less continuously over a three to five day period.

Freshly laid eggs begin swelling immediately. Swelling has the 


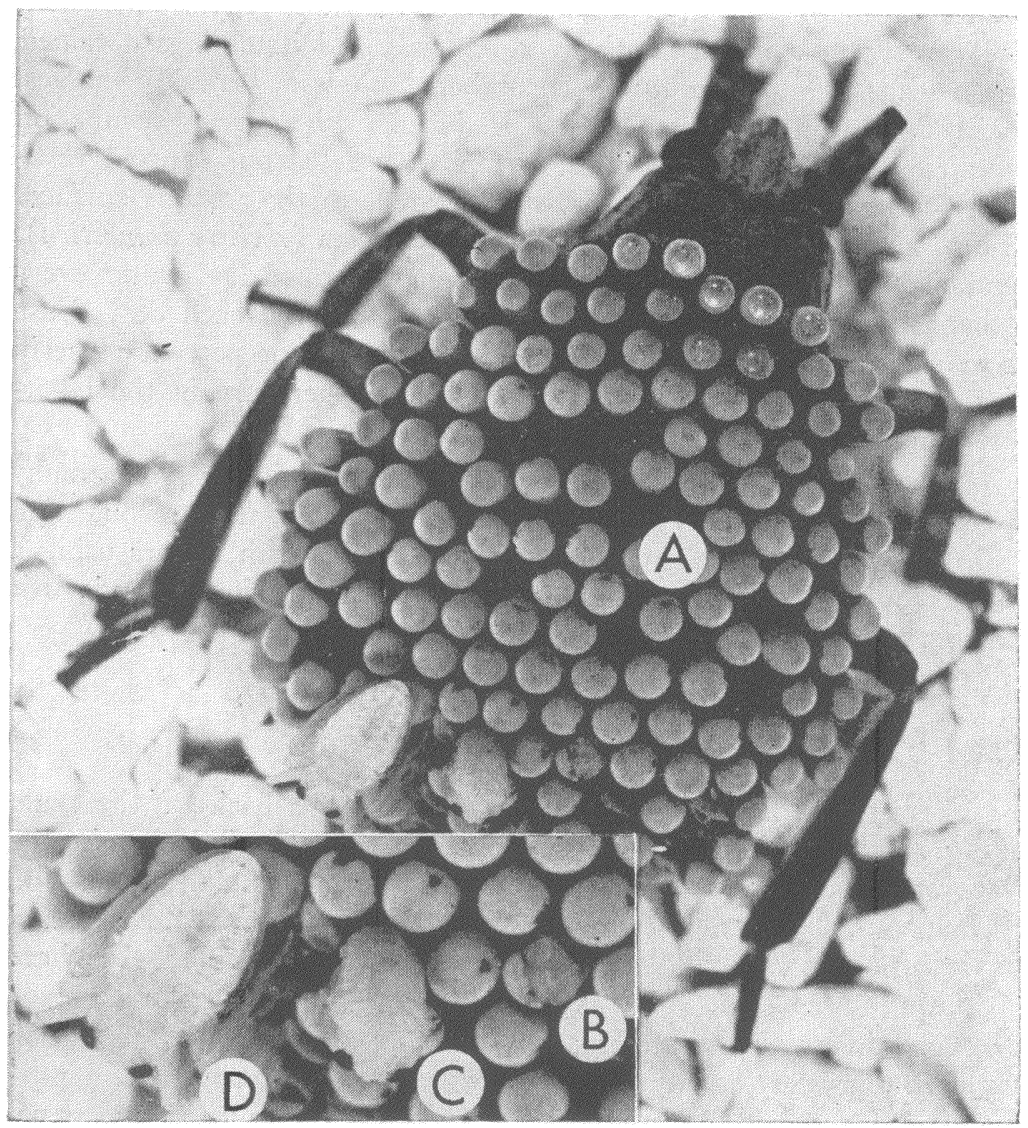

Figure 1. Encumbered male Abedus herberti and hatching of eggs.

A. Encumbered male Abedus herberti.

Inset. Enlargement of hatching nymphs.

B. Rupture of the chorion around cap.

C. Resting position.

D. Newly emerged nymph. 
ultimate effect of compacting the mass, enhancing its structural integrity and conformity to the male's back. The resulting gelatinous plate with its embedded eggs is strong, flexible and adheres tenaciously to the male's hemelytra so long as it is kept moist. If exposed to air for 60 minutes or longer, the gelatinous pad becomes brittle, loses its adhesive properties and on prolonged exposure will eventually fall off.

Eggs increase in size from mature oviducal $(3.064 \pm .022 \mathrm{~mm}$ by $\mathrm{I} .732 \pm .017 \mathrm{~mm}, \mathrm{n}=5 \mathrm{O}$ ) to those containing nymphs ready to hatch $(4.983 \pm .036 \mathrm{~mm}$ by $2.001 \pm .017 \mathrm{~mm}, \mathrm{n}=50)$. This represents a 59 percent mean increase in length and a 15.5 percent mean increase in width. The initial swelling of the egg (during the first 48 hours) may be due to imbibition of water, however later increase in size seems to be due to the development of the embryo. Both Hungerford (1925) and Tawfik (1969) noted dramatic increases in egg size during the development of Lethocerus eggs which are laid above the water on emergent vegetation. Cobben ( I968) provides a synthesis of what is known about belostomatid eggs and embryology.

Mature oviducal and freshly laid eggs are variable in shape, usually imperfect oval with one nearly straight side, yellow in color and irregularly hexagonal microreticulate. Soon after occlusion, eggs darken to tan. The cap (upper $1 / 3$ ) differentially darkens and remains several shades darker until just prior to eclosion of the nymph at which time it becomes grayish white in color. As development proceeds the shape of the egg comes to resemble an elongate "printed comma"; that is broad and rounded at the free end, narrow and pointed at the attached end, with one convex and one concave side. The concave side seems always to face the posterior of the mass. Cobben (1968, Fig. 232) shows the head of the embryo (of Sphaerodema $=$ Diplonychus $)$ facing the attached end, but embryonic rotation must occur prior to hatching. I observed one instance of egg failure due to nonrotation of the embryo.

\section{INCUBATION}

Male brooding of eggs, a complex of behaviors, is necessary for achievement of the greater than 95 percent survival observed for eggs of field-captured encumbered males. I never observed any type of egg parasitism. Egg failure, in every case but the one, seemed due to insemination failure; usually a few eggs on each plate did not develop. Open spaces in the laying pattern in Figure IA are undeveloped eggs. Harvey ( I906) reported that infertile eggs of Pedino- 


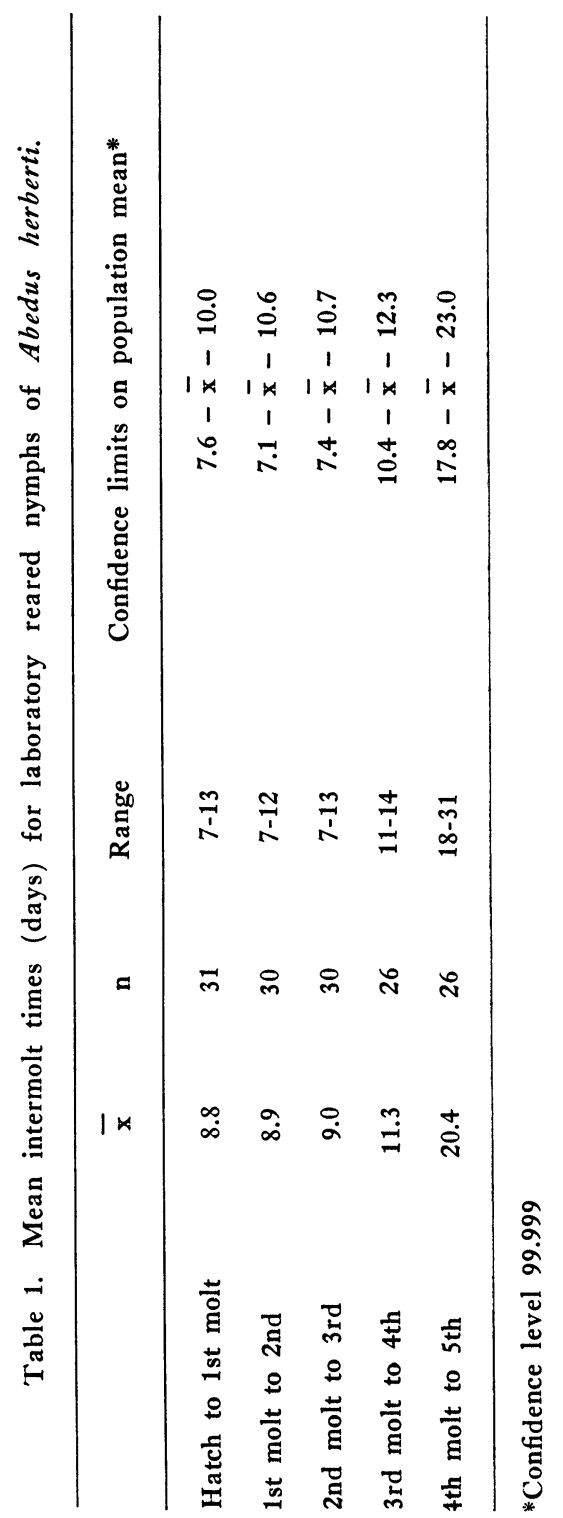




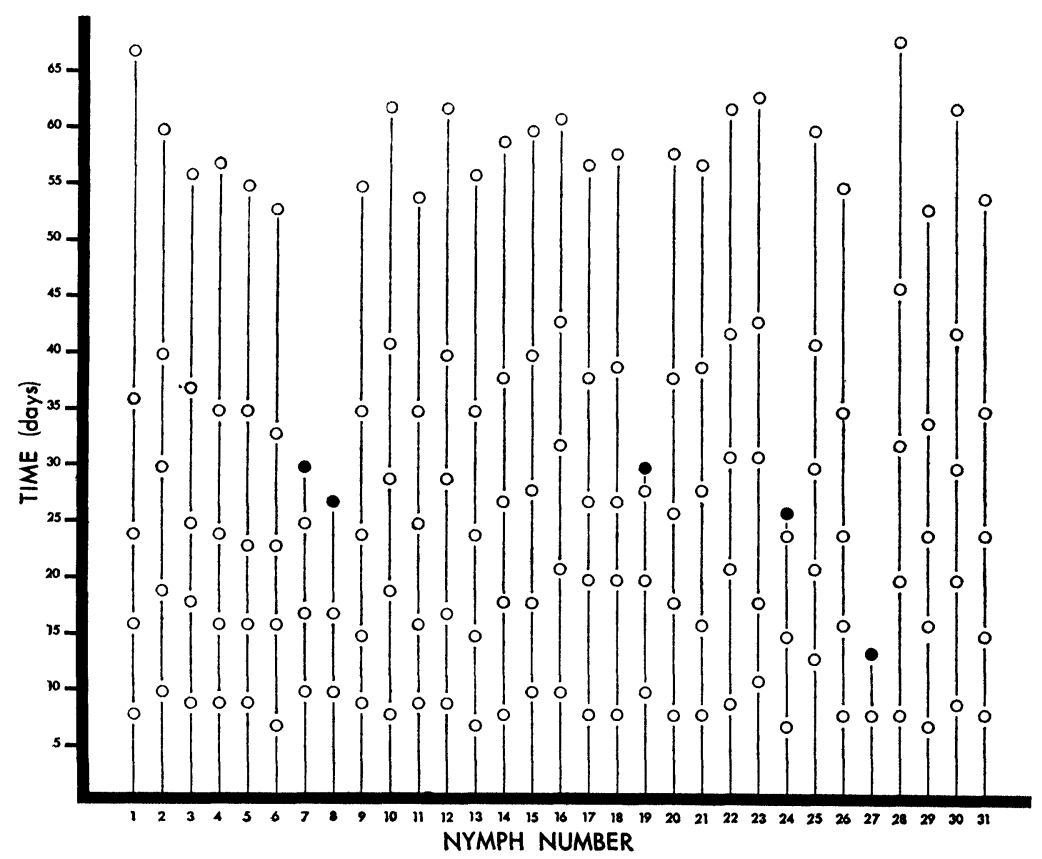

Figure 2. Individual molt records for 31 laboratory reared nymphs of $A$. herberti. Open circles indicate molts. Closed circles indicate the death of that nymph.

coris macronyx (= Abedus indentatus Haldeman) drop off and are replaced (presumably by the original or another female) by others as late as the sixth or eighth day of incubation, but in every instance I observed, nonviable eggs were retained in the nidus through incubation and hatching of the viable eggs. Incubation periods from laying of the first egg to hatching of the first ranged from 21 to 23 days in the laboratory. Voelker (1968) has shown developmental time for eggs of Limnogeton fieberi to be directly correlated with temperature, the optimal temperature being $32-33 \mathrm{C}$. He reports an 8 day development time at optimal temperatures, which seems to be more in agreement with the results obtained by the majority of other workers for belostomatids (Torre Bueno 1906, Harvey I906, Hungerford 1925, and Tawfik 1969). Menke (1960) found the incubation time for $A$. dilatatus to exceed 30 days in the laboratory, but we both (Menke, personal communication) suspect that development 
of eggs for Abedus could be substantially accelerated by increasing the temperature of the incubation water. Open water temperature in my laboratory ( $18 \mathrm{C}$ ) fell within the range of spring, fall and winter stream temperatures in Arizona.

\section{HATCHING}

Twenty-four hours prior to hatching, the free end of the egg swells dorsally. Pressure from within eventually causes a rupture in the chorion around the cephalic cap (Fig. IB). Invariably, nymphs hatch facing the brooding male's posterior. I can't explain this constant orientation of hatching nymphs, but its effect is that adjacent eggs can hatch simultaneously with a minimum of interaction between eclosing nymphs. The cap is lifted by the head as the nymphal thorax emerges, but remains hinged to the egg on the side of the latter which faces the ventral surface of the emerging nymph. The nymph's head slips from under the operculum as peristaltic contractions free one half of the body. When the nymph is two thirds removed, it rests in a position perpendicular to the plane of the $\mathrm{cgg}$ plate (Fig. IC). Moments later it arches backward and stretches its legs which are employed in final extraction when the nymph again leans forward. A newly emerged bug generally lingers on the back of the male for several minutes to inflate its laterally constricted abdomen (Fig. ID). This accomplished, it moves off in search of cover among aquatic plants or debris where it assumes the predatory stance characteristic of nymphs and adults alike. Freshly emerged nymphs are light honey yellow in color and translucent, but darken within one hour.

\section{Nymphal Development and Nymphs}

\section{DEVELOPMENT}

Of 31 nymphs reared in the laboratory, 26 survived to adulthood. Individual developmental records are illustrated in Fig. 2 and mean developmental periods are presented in Table I. These results compare favorably with those of Voelker (1968) for Limnogeton and probably reflect critical minimum periods required for morphogenesis between molts under optimal conditions. That availability of food is an important factor related to intermolt time for these sedentary hunters was demonstrated in a simple experiment. Ten of 20 sibling first instars, fed Drosophila daily, all molted in under eight days while the other ten, fed every fourth day, did not begin to molt until the nineteenth day. Thirty additional sibling first instars were di- 


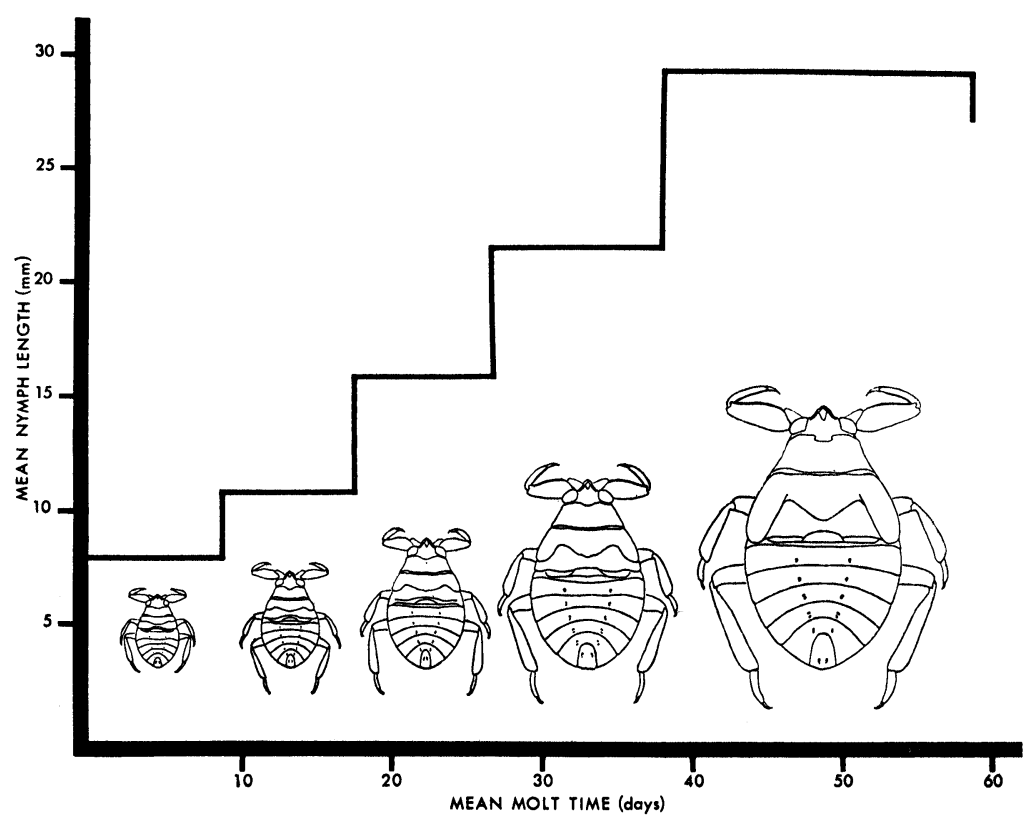

Figure 3. First through fifth instar nymphs of $A$. herberti. Mean length and mean duration of instars illustrated graphically.

vided into three groups of ten individuals. Each group was kept at a different temperature ( $18 \mathrm{C}, 22 \mathrm{C}$, and $3 \mathrm{I} \mathrm{C}$ ) and all nymphs received Drosophila daily in numbers exceeding that which they could consume. All molted at approximately the same time (on the sixth or seventh day), suggesting that temperature is relatively unimportant. These experiments were not intended to be conclusive and it is probable that a food-temperature interaction could be detected with more sophisticated experimentation.

\section{NYMPHS}

There are five nymphal instars for $A$. herberti. Dorsal views of the five are figured (Fig. 3) and mean morphometric data for fifteen characters of each instar are presented in Table 2. The wide (.oor) confidence limits around each mean should encompass interpopulation variation for central Arizona. Mean size of bugs seems to be stream specific, perhaps due to low dispersal of these animals and reduced gene flow between their populations. $A . h$. herberti intergrades with 
a smaller subspecies $A$. h. utahensis in northern Arizona and southern Utah.

The first through the fourth instars all have two segmented antennae and one segmented pro-, and two segmented meso- and metatarsi. The beak is four segmented from the first instar to imago. One antennal segment is added in the fifth instar and usually another in the adult. All tarsi add one segment in the adult molt.

The most noteworthy changes through instars are the allometric development of the wing pads (Fig. 3) and of the protarsal claws. Torre Bueno (1906) states that there is a progressive diminution in size (through the instars) of the anterior (external) protarsal claw of Belostoma fumineum and that the external claw finally disappears in the adult. This statement is erroneous on at least one count, but nevertheless focuses attention on an ontological aspect of phylogenetic significance. It is now known (Lauck and Menke I96I) that both Belostoma and Abedus have vestigial external protarsal claws. The other three genera in the Belostomatinae have two well developed protarsal claws as does the genus Lethocerus. In Abedus herberti, and probably Belostoma as well, only the magnitude of the size difference between the external and internal protarsal claws increases with each molt due to nondevelopment of the external claw and continued growth of the internal. In the first instar relative length of the external claw is 50 percent of the internal. This is reduced to about 38 percent in the second, 30 percent in the third, 23 percent in the fourth, and 19 percent in the fifth instar. Curiously, in the adult the external is proportionally slightly longer than in the fifth instar and the internal claw is shorter and broader in the adult. This results in an increase in the relative length of the external claw to about 28 percent that of the internal in the adult bug.

\section{LONGEVITY}

$A$. herberti is a relatively large animal and is a sedentary hunter, both of which characteristics suggest that it might be long lived. This seems to be the case; several specimens have lived in the laboratory for up to one year and one in particular, a female collected on October 14, 1972, lived until November 30, 1973 during which time she produced four sets of eggs totaling 344. Nymphs from the first through the third instars are probably subject to predation by other aquatic organisms. I have found first instar nymphs in the stomachs of trout taken at three forks of the Black River, Apache County, Arizona. Nymphal instars seem to play an important role in the 
food economy of the species during periods of low stream productivity; I commonly find nymphs and adults feeding on smaller nymphs of their own species. After the second instar, cannibalism seems to be far the most common cause of fatality among nymphs. Ecdysal failure and physical catastrophes (flood and drought) also regulate populations. Lethocerus adults, which are seasonally common but never abundant in Sonoran streams, may regularly take adult Abedus but I have observed only one instance of this. In general, $A$. herberti adults are at the pinnacle of the aquatic food chain, and, having reached adulthood, stand an excellent chance of surviving to produce or brood several clutches of eggs.

\section{Discussion}

The life history of Abedus herberti seems to follow closely the pattern reported for other genera belonging to the subfamily Belostomatinae. Allometric development of the protarsal claws closely relates Abedus to Belostoma, and suggests their common ancestry with the two clawed genera. Five instars is the number characteristic of acquatic Hemiptera (Hungerford 1920).

\section{Acknowledgements}

I wish to thank Dr. M. Parsons, Dr. A. S. Menke, and Dr. J. Alcock for review.

\section{Literature Cited}

Cobben, R. H.

1968. Evolutionary trends in Heteroptera. Part I Eggs, architecture of the shell, gross embryology and eclosion. Center for Agricultural Publishing and Documentation, Wageningen, Netherlands. Pp. 206-209.

Cullen, M. J.

1969. The biology of giant water bugs (Hemiptera: Belostomatidae) in Trinidad. Proc. R. Ent. Soc. Lond. (A) 44: 123-137.

De Carlo, J. M.

1962. Consideraciones sobre la biologia de Lethocerus mazzai De Carlo. Physis, 23 : 143-151.

Harvey, G. W.

1906. A ferocious water-bug. Proc. Ent. Soc. Wash., 8: 72-75.

HUNGERFORD, H. B.

1920. The biology and ecology of aquatic and semiaquatic Hemiptera. Kansas Univ. Sci. Bull., 11: 1-328.

1925. Notes on the giant water bugs. Psyche, 32: 88-91. 
LaUck, D. R. and A. S. MenKe

1961. The higher classification of the Belostomatidae (Hemiptera). Ann. Entomol. Soc. America, 54: 644-657.

MeNKe, A. S.

1960. A taxonomic study of the genus Abedus Stål (Hemiptera, Belostomatidae). Univ. Calif. Pub. in Entomol., 16:393-440.

RANKIN, K. P.

1935. Life history of Lethocerus americanus (Leidy) (Hemiptera, Belostomatidae). Kansas Univ. Sci. Bull., 15: 479-491.

SchNACK, J. A.

1971. Las ninfas del genero Belostoma Latreille (Hemiptera, Belostomatidae) (I) Belostoma oxyurum (Dufour) y Belostoma bifoveolatum Spinola. Rev. Soc. Ent. Arg., 33 : 77-85.

TAWFIK, M. F. S.

1969. The life history of the giant water-bug Lethocerus niloticus Stael (Hemiptera: Belostomatidae). Bull. Soc. Ent. Egypte, 53: 299310.

Torre Bueno, J. R.

1906. Life history of North American water bugs. I. Life history of Belostoma flumineum Say. Can. Ent., 38: 189-197.

VOELKER, J.

1968. Untersuchungen zu Ernährung, Fortpflanzungsbiologie und Entwicklung von Limnogeton fieberi Mayr (Belostomatidae, Hemiptera) als Betrag zur Kenntnis von natürlichen Feinden tropishen Süsswasserschnecken. Entomologishe Mitteilungen, 3(60): 1-24. 

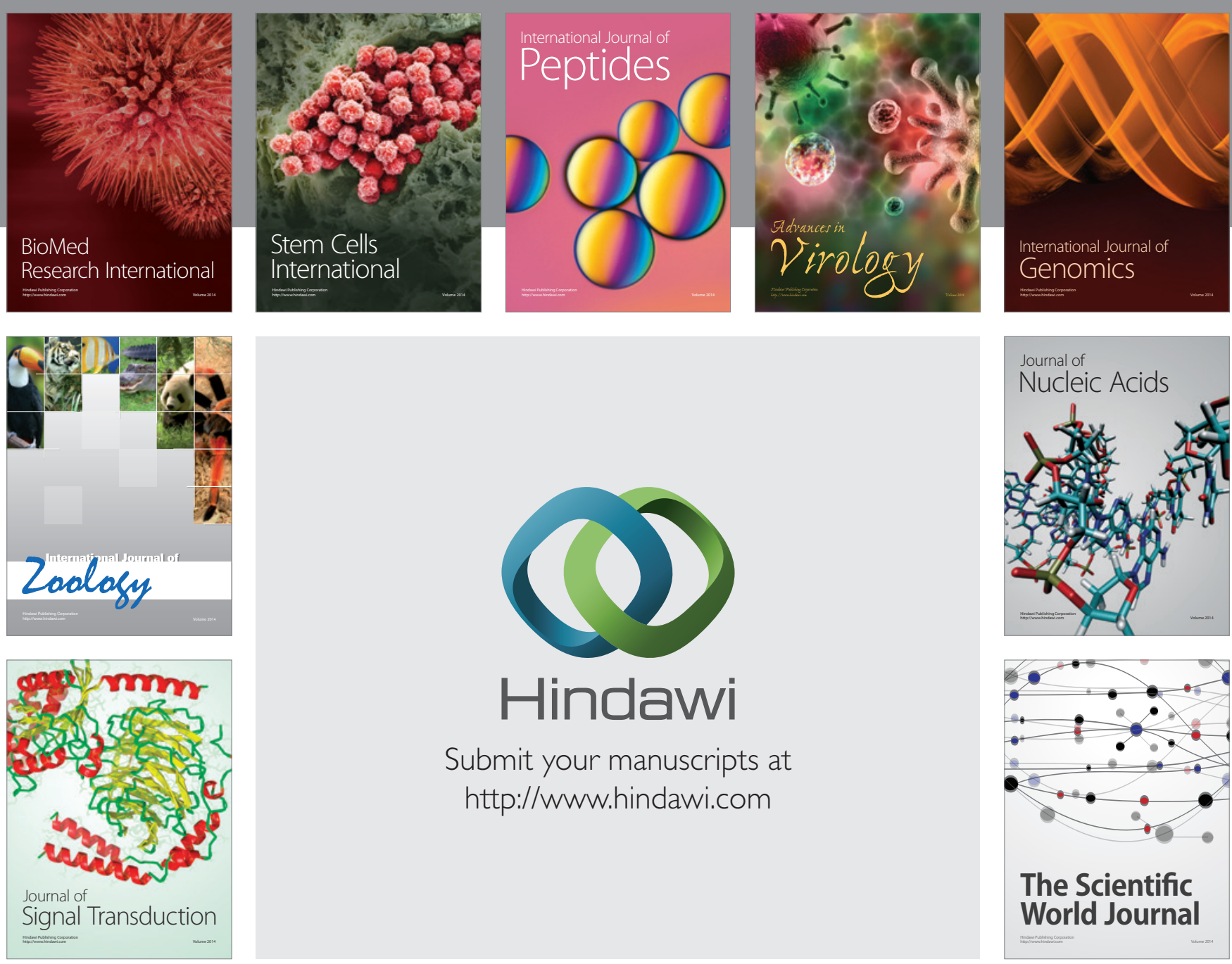

Submit your manuscripts at

http://www.hindawi.com
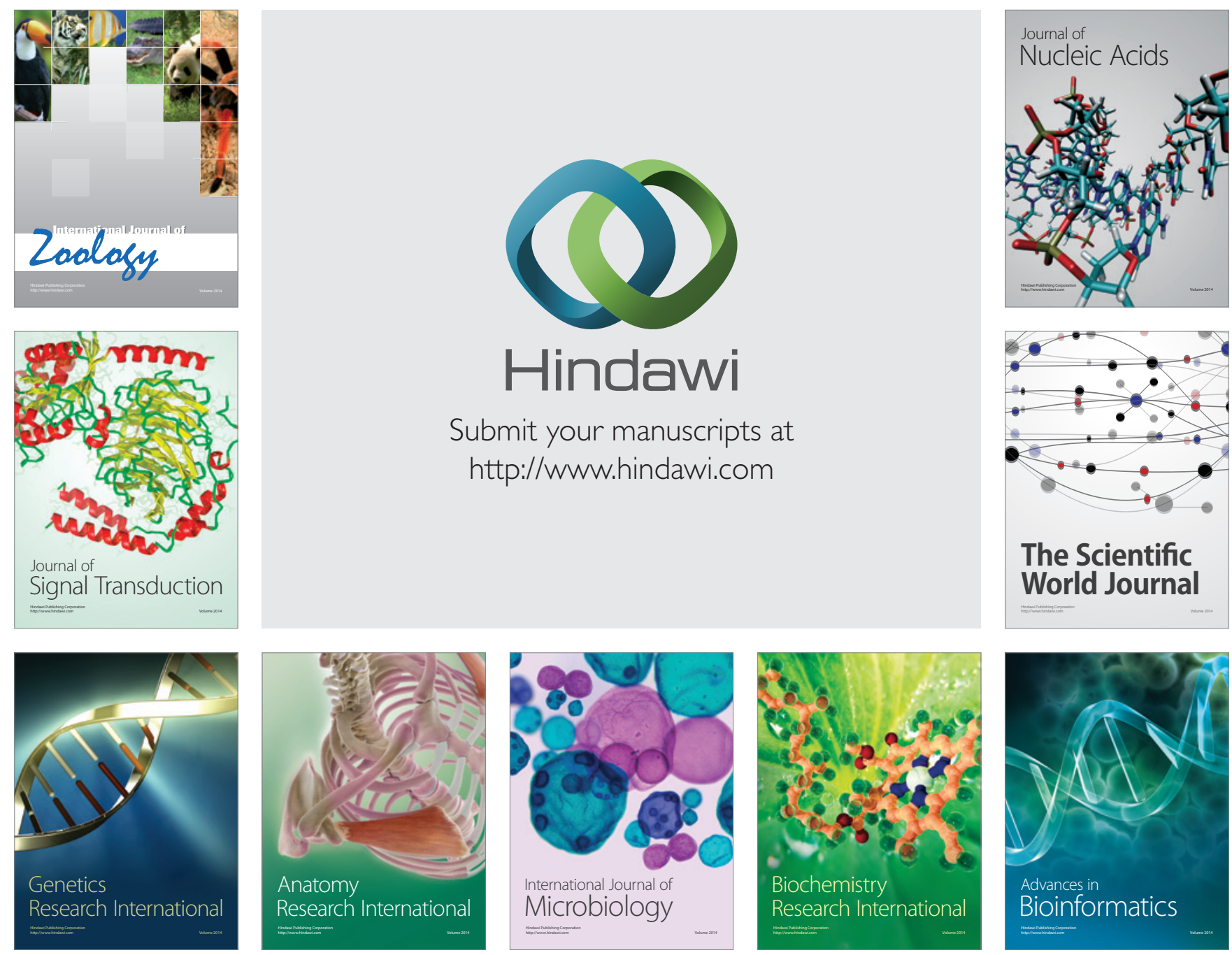

The Scientific World Journal
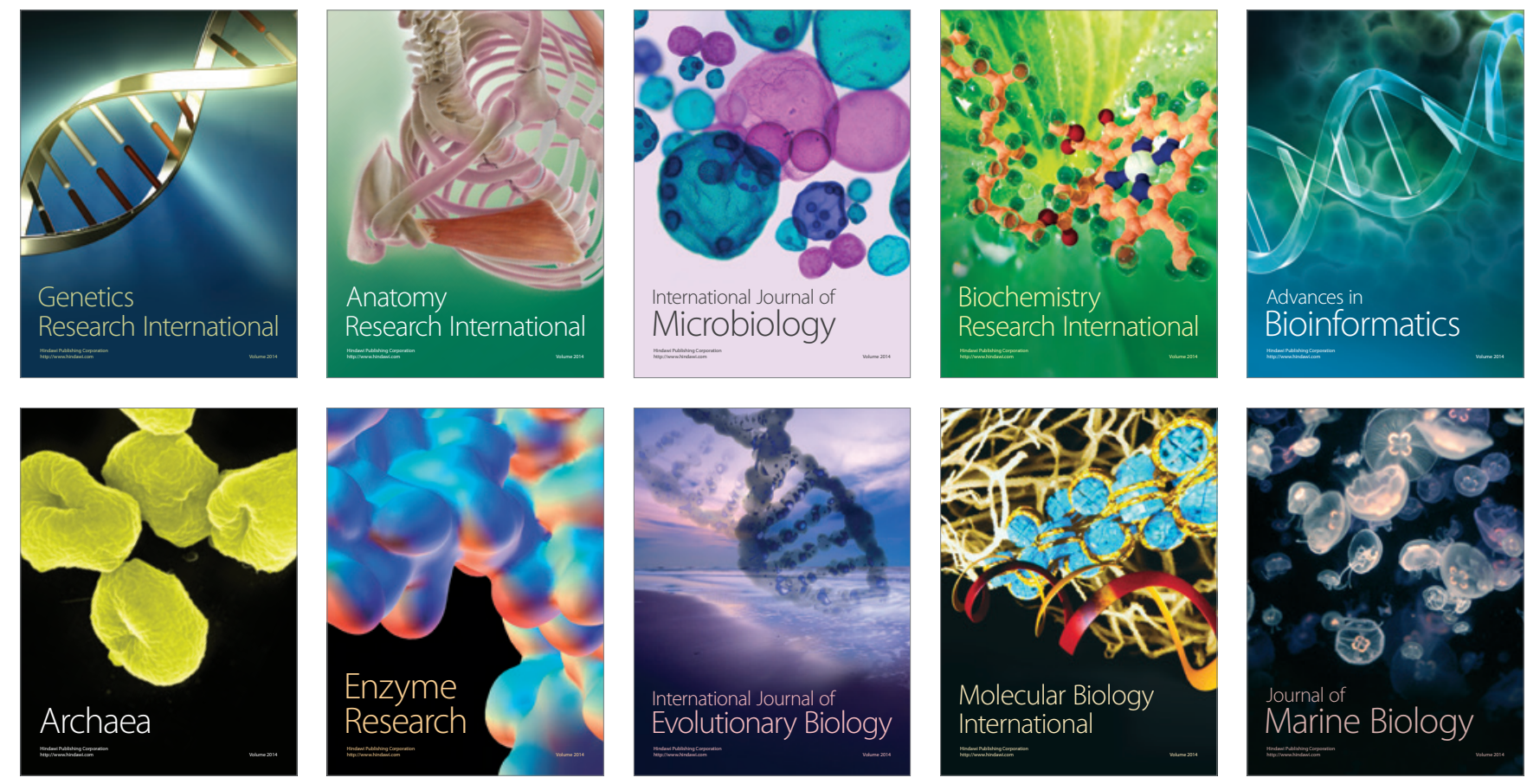